\title{
Implementation of Chemical Health Risk Assessment (CHRA) Program at Chemical Laboratories of a University
}

\author{
Mohsin Abbas ${ }^{1,2}$ (Corresponding author) \\ ${ }^{1}$ Department of Environmental Sciences, Faculty of Sciences, University of Gujrat, \\ Hafiz Hayat Campus, Jalalpur Road, Gujrat, Pakistan \\ E-mail: mohsin.abbas@uog.edu.pk; myousaf@stu.kau.edu.sa
}

Tel: 92-30-2660-2001

${ }^{2}$ Department of Environmental Sciences,

Faculty of Meteorology Environment Arid Land Agriculture, King Abdul-Aziz University, Jeddah, Saudi Arabia

\author{
Adel M. Zakaria \\ Department of Environmental Sciences, \\ Faculty of Meteorology, Environment and Arid Land Agriculture, King Abdul-Aziz \\ University, \\ Jeddah, Kingdom Saudi Arabia
}

\author{
Mansour A. Balkhyour \\ Department of Environmental Sciences,
}

Faculty of Meteorology Environment Arid Land Agriculture, King Abdul-Aziz University, Jeddah, Saudi Arabia

Received: April 23, 2017 Accepted: May 2, 2017 Published: May 8, 2017

doi:10.5296/jss.v3i1.11109 URL: https://doi.org/10.5296/jss.v3i1.11109 


\section{Abstract}

The use of chemicals in academic/research laboratories is obvious which need proper university's safety management. It is the prime responsibility of university top management to protect laboratory staff from chemical health risks during their work. This study elaborates a methodology for the implementation of a Chemical Health Risk Assessment (CHRA) program in a University's chemical laboratories. The objective of this CHRA program is to identify and evaluate the risks of chemical exposure among laboratory staff. The qualitative observation of CHRA program identified two categories of risk, one is a significant risk but already adequately controlled could increase in future, second is risk significant now, and not adequately controlled. Based on the conclusion of CHRA program proactive suggestions were made to reduce the risks of chemical exposure among laboratory staff. This study can be useful to implement CHRA program in chemical laboratories of a university to assess the risk of chemical exposure and required control measures for the protection of laboratory staff.

Keywords: Chemical exposure; Occupational risk assessment; Chemical Safety; Laboratory Safety; Kingdom of Saudi Arabia

\section{Introduction}

The use of diverse chemicals in academic laboratories is obvious, especially for research oriented working units. It is a wrong perception that academic laboratories are safe vanes of work for students and researchers (Shariff \& Norazahar, 2011), as it was found that majority of them are unsafe for study and research. The use of small quantities of chemicals in academic laboratories can be a reason for this wrong perception. Chemical risk exposure in research/academia increased with the development and diversification of new techniques and materials into the field of Science as recent accidents shows; Blast in a French University (Freemantle, 2006), Blindness of a laboratory staff in University of technology, Taiwan (Wu et al., 2007), severe injuries due to Explosion of perchlorate in a University (Kemsley, 2010).Recognition of laboratory safety as compared to the safety of industrial manufacturing plants is still a challenge for health and safety of laboratory staff. Due to lack of resources, less attention has been paid to chemical risk evaluation and mitigation in the universities of developing countries.

It is important to know about the risk of chemical exposure to the laboratory staff of academic and research institutes. To evaluate chemical risk assessment, several approaches have been found in literature as; a systematic approach in the form of an online software tool named Lab-HIRA (Hazard Identification and Risk Analysis for the Chemical Research Laboratory) to conduct a risk assessment (Leggett, 2012 $2_{\mathrm{a}, \mathrm{b}, \mathrm{c}}$ ), Lab-HIRA can be useful to decrease chemical accidents in the laboratories during chemical synthesis process after the implementation of risk minimization measures but this technique can be expensive for and time taking to get in-depth analysis. A comparative study designed to analyze three methods to identify chemicals hazards in French laboratories but this study focused mainly on chemical hazards, not chemical exposure (Bourrée et al., 2014). A zero ventilation model (tiered approach) developed for chemical exposure assessment (air concentration) of ethyl ether, n-hexane, and methylene chloride in a chemistry teaching laboratory during distillation 
and extraction exercises (Keil \& Murphy, 20006) this exposure model can be a useful tool to assess the acceptability of chemical exposure, but this study cannot adopt as it is for whole chemical inventory of laboratories in universities. A model for identification of hazardous chemical hazards in biomedical laboratories proposed which can be useful only for health and epidemiological surveillance programs for laboratory workers (Apostoli et al., 1996). Recently a model named "Chemical Hazard Evaluation for Management Strategies" (CHEMS-1) used for the development of a framework for scoring of analytical laboratories solvents by calculating hazards values extracted from toxicological and exposure data (Tobiszewski \& Namieśnik, 2015) A hazards mapping tool proposed for the classification of 28 specific laboratory hazards including chemical hazards named Assessment and Classification of Hazards in Laboratories (ACHiL) (Marendaz et al., 2013). This study useful only regarding classification and assessment of a broad range of diverse laboratories hazards. A methodology developed named "Laboratory Assessment and Risk Analysis" (LARA) based on the calculation of Lab Criticity Index (LCI) (Ouédraogo et al., 2011). LARA is useful to estimate the risk regarding the combination of severity, probability, detectability, worsening factors and research specificities. A systemic technique named "Laboratory at-risk behavior and improvement system" (Lab-ARBAIS) developed to monitor and control students' at-risk behavior in the laboratory (Shariff \& Norazahar, 2011). Lab-ARBAIS can be useful to monitor students' at-risk behavior to ensure healthy workplace but deficient regarding amount or extent of risk. A broader concept of academic safety management proposed and discussed in a study named MICE (Management, Information, Control and Emergency). MICE approach also deals with chemical management in the universities (Meyer, 2012).

As earlier mentioned about the recognition issue of laboratory safety and fewer resources in the developing countries we tried to implement an approach as a preliminary step to create safety culture there. We applied chemical health risk assessment (CHRA) technique for the assessment of chemical risks in a Saudi university. Previously, this method was used in a Malaysian University for chemical health risk assessment of teaching and research labs in chemical and biochemical engineering department (Husin et al., 2012). This study explains the detail implementation of CHRA program.

A CHRA program instituted in the chemical laboratories. The purpose of the CHRA program is to identify and evaluate the risks and level of chemical exposure among laboratory staff (students and researchers). This program also evaluates the adequacy of existing control measures also of exposure chemical mitigations relatively.

\section{Materials and Methods}

For the implementation of CHRA, we adopted methodology from a manual named "Assessment of the Health Risks Arising from the Use of Hazardous Chemicals in the Workplace" developed by the department of occupational safety and health, Malaysian Ministry of human resources (CHRA, 2000). Flow chart of CHRA program with the five types of conclusions has been given in Figure 1. The purpose of a CHRA is to enable University top management for decision making of the protection of students and laboratory 
staff who may expose to occupational chemical exposure, based on appropriate control measures.

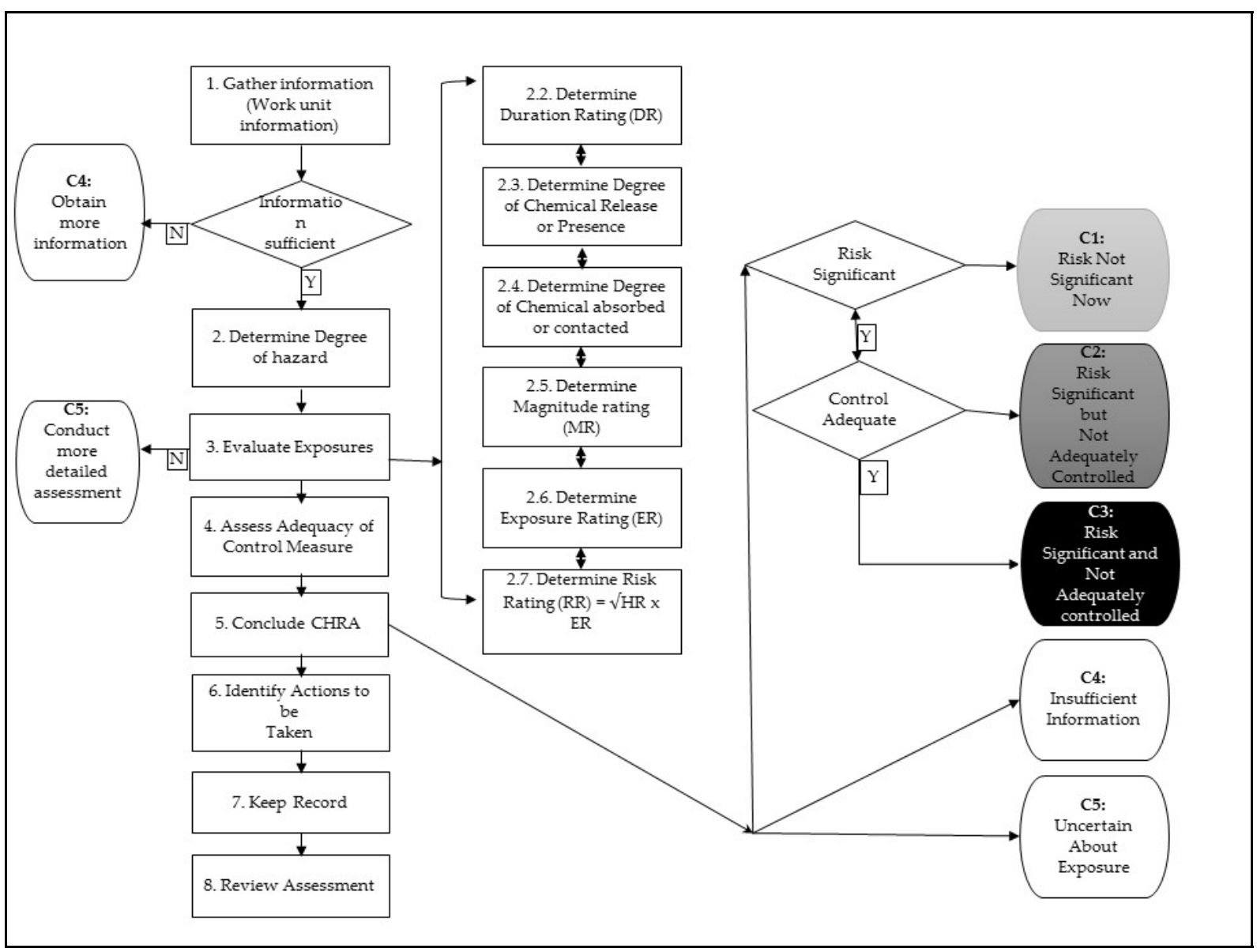

Figure 1. Flow chart of Chemical Health Risk Assessment (CHRA) adopted and modified from (CHRA, 2000)

We used the results of a preliminary study (Abbas et al., 2016) in order to select the worst chemical laboratories, and total 14 chemical laboratories have been chosen to conduct CHRA as Table 1 shows the details of chemical laboratories. Material safety data sheets (MSDS) from supplier used as primary source of information for chemicals exposure risk and related OHS information such as; Laboratory working hours, Personal protective equipment (PPE) programme, control equipment design parameter and maintenance (fume hood design parameters, local exhaust ventilation and inspection records) has been assessed during CHRA. We reviewed frequent laboratory tasks both routine and non-routine, production of one-off items to identify all potential risks. We conduct regular walk-through surveys to identify the risk of chemical exposure to laboratory staff. 
Table 1. List of chemical laboratories

\section{Lab Chemical Laboratory No. of frequently chemicals}

L1 Analytical Chemistry Lab 1 16

L2 Natural Product Chemistry Lab $\quad 10$

L3 Analytical Chemistry Lab 2 16

L4 Preparation lab 3

L5 Electrochemistry lab $\quad 11$

L6 Organic chemistry lab 5

L7 Instrumental analysis lab $\quad 9$

L8 Local Ores Lab $\quad 21$

L9 Research Lab 15

L10 Analytical Chemistry Lab $3 \quad 8$

L11 Solid waste Lab 17

L12 Nanotechnology research lab $\quad 15$

L13 Plant Biotechnology Lab 3

L14 Microbiology Lab 4

$L=$ Chemical laboratory

\subsection{Determination of Duration Rating (DR)}

Table 2 used for the determination of DR stratified with working hours. For example DR value 1 ( $<1 \mathrm{hr}$. $/ 8 \mathrm{hrs}$. day or $<5$ hours/ week) is minimum and DR value 5 ( $>7 \mathrm{hrs}$. /day or $>35$ hours/ week) is maximum). 
Table 2. Duration rating (DR) assigning Criteria for chemical laboratories

\begin{tabular}{|c|c|c|c|c|}
\hline \multirow{2}{*}{$\begin{array}{l}\text { Rating } \\
5\end{array}$} & \multirow{2}{*}{$\begin{array}{l}\text { \% work hour } \\
>87.5 \%\end{array}$} & \multicolumn{3}{|c|}{ Duration per 8-hr shift or per 40 -hr week } \\
\hline & & $>7$ hrs./ day & or & $>35$ hours/ week \\
\hline 4 & $50-87.5 \%$ & 4 to $7 \mathrm{hrs} . /$ day & or & 20 to 35 hours/ week \\
\hline 3 & $25-50 \%$ & 2 to $4 \mathrm{hrs} . /$ day & or & 10 to 20 hours/ week \\
\hline 2 & $12.5-25 \%$ & 1 to $2 \mathrm{hrs} . /$ day & or & 5 to 10 hours/ week \\
\hline 1 & $<12.5 \%$ & $<1$ hr. / 8 hrs. day & or & $<5$ hours/ week \\
\hline
\end{tabular}

*Note: Total exposure duration per week $(T D)=$

(Number of exposure per week) x (Average duration of each exposure)

\subsection{Qualitative Estimation of Magnitude of Exposure}

There are two main routes of entry for chemicals exposure i.e. inhalation route and dermal route. In the case of ingestion, if chemical exposure is significant, make the evaluation and recommend suitable actions to be taken. The magnitude of chemical exposure can be estimated through the assessment of absorbed chemicals dose via inhalation and skin absorption. Chemical exposure to skin or eye in the form of absorption is not only from direct contact with solvents; but it can also be through airborne gas, vapors or particulates. So for the qualitative estimation of the magnitude of chemical exposure, we determined the degree of a chemical release or presence and the degree of chemical absorbed or likely absorbed (contacted) in selected chemical laboratories (CHRA, 2000).

\subsection{Determination of Degree of Chemical Release (Presence)}

The degree of chemical release (presence) estimated based on the following information;

1. Physicochemical properties of chemicals availed through Material safety data sheet (MSDS) of chemicals

2. Characteristics of work process availed through description of chemical process

3. Chemicals used quantity availed through laboratory chemicals register

4. Methods of chemical handling availed through onsite personal observations

5. Atmospheric conditions availed through onsite observations of environmental conditions. 
Table 3 used to assign the degree of chemicals release (presence) for inhalation exposure after onsite personal observations. For example, if clothing of a laboratory worker is getting frequently contaminated while using a non-volatile liquid (i.e. minor release into the air) but is lipophilic (high ability to dissolve fat and hence able to absorb through the skin), assigned degree of a chemical release or presence will be Moderate.

Table 3. Degree of Chemical Release or presence

\begin{tabular}{l|l}
\hline Degree & \multicolumn{1}{l}{ Sample observation } \\
\hline \multirow{2}{*}{ Low } & $\begin{array}{l}\text { Low or little release into the air. } \\
\text { No contamination of air, clothing and work surfaces, with chemicals capable of } \\
\text { skin absorption or causing irritation or corrosion. }\end{array}$ \\
\hline \multirow{5}{*}{ Moderate } & $\begin{array}{l}\text { Moderate release such as; } \\
\text { a) Solvents with medium drying time in uncovered containers or exposed to } \\
\text { bork The detectable odor of chemicals with odor thresholds exceeding the PELs. }\end{array}$ \\
\hline \multirow{5}{*}{ High } & $\begin{array}{l}\text { Evidence of contamination of air, clothing and work surfaces with chemicals } \\
\text { capable of skin absorption or causing irritation or corrosion. }\end{array}$ \\
\hline $\begin{array}{l}\text { Substantial release such as; } \\
\text { a) Solvents with fast drying time in uncovered containers; } \\
\text { b) Sprays or dust clouds in poorly ventilated areas; } \\
\text { c) Chemicals with high rates of evaporation exposed to work environment; } \\
\text { d) A Strong odor of chemicals with odor thresholds exceeding the PELs. }\end{array}$ \\
$\begin{array}{l}\text { Gross contamination of air, clothing and work surfaces with chemicals capable } \\
\text { of skin absorption or causing irritation or corrosion. }\end{array}$ \\
\hline
\end{tabular}

The qualitative estimation of chemical exposure based on industrial hygiene professional judgment by following an exposure model given in Figure 2. Industrial hygiene judgment made on the basis that the amount of chemical absorbed (contacted) or in contact with laboratory staff body depends on the degree of a chemical release (presence) and the degree of reception (retention). Following factors can affect chemical inhalation exposure such as; contaminant release rate, quantity used or handled, air contamination, in the vicinity of the source and in enclosed/confined space where the contaminant is present (CHRA, 2000). Following factors can affect the degree of reception or retention such as; work practice, air intake, contaminated clothing \& surfaces, workers awareness and personal hygiene. 


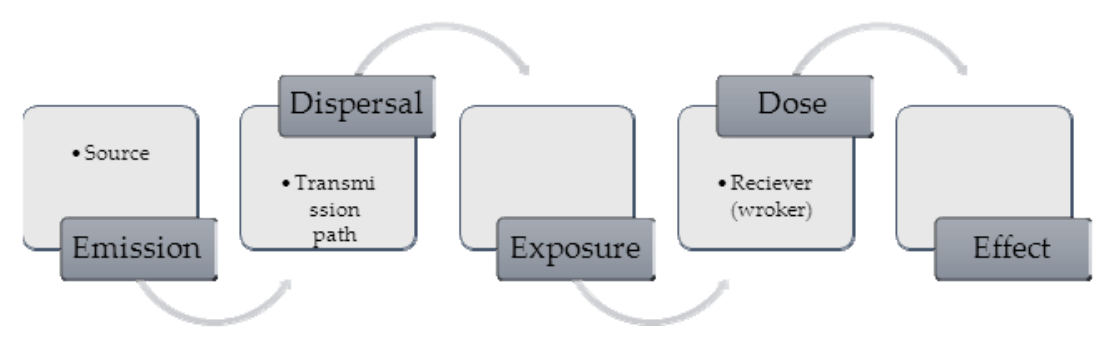

Figure 2. Outline of qualitative exposure model (CHRA, 2000)

\subsection{Determination of Degree of Chemical absorbed (contacted)}

The degree of chemical absorbed (contacted) determined by using Table 4. Organic solvents can absorb through the skin. Onsite observation of chemical laboratory made accordingly, and the degree of chemical absorbed or contacted assigned.

Table 4. Determination of Degree of Chemical absorbed or contacted

\begin{tabular}{l|l}
\hline Degree & Sample observation \\
\hline Low & $\begin{array}{l}\text { Low breathing rate (light work }>\text { Sitting, moderate arm and trunk movements } \\
\text { (E.g. desk work, typing) } \\
\text { Cource far from breathing zone } \\
\text { "High". } \\
\text { A small area of contact with chemicals capable of skin absorption-limited to } \\
\text { palm (intact skin). }<2 \% \text { or } 0.04 m 2 \\
\text { No indication of any skin conditions. Intact/normal skin } \\
\text { No contamination of skin or eyes }\end{array}$ \\
\hline Moderate & $\begin{array}{l}\text { Moderate breathing rate (moderate work }>\text { sitting, heavy arms and legs } \\
\text { movement (standing, light work at machine or bench, some walking about, } \\
\text { Standing, moderate work at machine or bench, Walking about, with moderate } \\
\text { lifting or pushing) } \\
\text { Source close to breathing zone } \\
\text { Contact with eye or skin irritants, sensitizers or chemicals capable of skin } \\
\text { penetration, except those described under 'High'. } \\
\text { Moderate area of contact- one or both hands up to the elbows. }\end{array}$ \\
\hline
\end{tabular}




\begin{tabular}{l|l}
\hline & $\begin{array}{l}\text { Skin area }>2 \% \text { or } 0.04 \mathrm{~m}^{2} \\
\text { Skin dryness and detectable skin condition. Dry, red skin }\end{array}$ \\
\hline \multirow{3}{*}{ High } & $\begin{array}{l}\text { High breathing rate (heavy work }>\text { Intermittent heavy lifting, pushing or pulling } \\
\text { A source within breathing zone. } \\
\text { Gross contamination of eye or skin with skin or eye irritants, } \\
\text { Sensitizers or chemicals capable of skin absorption -skin soaked or immersed in } \\
\text { chemical capable of skin penetration. } \\
\text { Area of contact not only confined to hands but also other parts of the body. Skin } \\
\text { area }>50 \% \text { or } 1 \mathrm{~m}^{2}\end{array}$ \\
$\begin{array}{l}\text { Follicle rich areas. } \\
\text { Skin damaged. } \\
\text { Severe drying, peeling and cracking. }\end{array}$
\end{tabular}

\subsection{Determination of Magnitude Rating (MR)}

Based on Table 3 and Table 4, we assigned the degree of a chemical release (presence) and the degree of chemical absorbed (contacted). For determining MR, we used Table 5. The first column belongs to the degree of a chemical release (presence), the second column belongs to the degree of chemical absorbed (contacted), and the third column belongs to the relevant MR numeric number ( $1=$ lowest, $5=$ highest $)$.

\subsection{Determination of Exposure Rating (ER)}

ER is a product of DR and MR. Matrix for ER in Table 6 used to assign ER to each chemical laboratory.

Table 5. Magnitude Rating (MR)

\begin{tabular}{c|c|c}
\hline Degree of release & Degree of absorbed & MR \\
\hline \multirow{3}{*}{ Low } & Low & 1 \\
& Moderate & 2 \\
& High & 3 \\
\hline \multirow{2}{*}{ Moderate } & Low & 2 \\
& Moderate & 3 \\
& High & 4 \\
\hline \multirow{2}{*}{ High } & Low & 3 \\
& Moderate & 4 \\
\hline
\end{tabular}


Table 6. Matrix for Exposure Rating (ER)

\begin{tabular}{cccccc}
\hline Duration Rating (DR) & \multicolumn{5}{c}{ Magnitude Rating(MR) } \\
\hline $\mathbf{1}$ & $\mathbf{1}$ & $\mathbf{2}$ & $\mathbf{3}$ & $\mathbf{4}$ & $\mathbf{5}$ \\
$\mathbf{2}$ & 1 & 2 & 2 & 2 & 3 \\
$\mathbf{3}$ & 2 & 2 & 3 & 3 & 4 \\
$\mathbf{4}$ & 2 & 3 & 3 & 4 & 4 \\
$\mathbf{5}$ & 2 & 3 & 4 & 4 & 5 \\
\hline
\end{tabular}

\subsection{Determination of Hazard Rating (HR)}

The purpose of HR calculations is to prioritize types of potential health hazards due to chemical exposure, rated on a scale range of $1-5$ ( $1=$ not hazardous, $5=$ most hazardous). MSDS can be used to assign the risk phrases to each chemical for determination of HR. At first, we assigned HR to individual chemical and in the last column of Table 6 which is given in supplementary material. We assigned HR to the mixture of chemicals. All frequently used chemicals in a chemical laboratory, we consider it as a mixture or preparation to assign the accumulative HR. First of all, we classified chemical hazards, and risk phrases and Table 7 used to assign hazard rating. In the case of a mixture of chemical (like a laboratory use different types of chemicals), we assigned a single hazards based on the greatest degree of hazard.

\subsection{Determination of Risk Rating (RR)}

Risk rating (RR) is square root of $\mathrm{HR}$ times ER, formulated as;

$$
\mathrm{RR}=\sqrt{\mathrm{HR}} \times \mathrm{ER}
$$

Matrix for RR in Table 8 used to assign RR to each chemical laboratory. Two possible cases can be seen after determination of RR i.e. risk is significant or risk is not significant. For example, if there is no likelihood of chemical exposure or chemical is least hazardous $(\mathrm{HR}=1)$ or low chemical exposure $(\mathrm{ER}=1)$. Another possible scenario of nonsignificant risk can be such as; chemical with low toxicity $(\mathrm{HR}=2)$ and below 0.5 PEL exposure level $(\mathrm{ER}=2)$. So RR from 1 or 2 can be considered as non-significant. 
Table 7. Hazard Rating Based on Risk Phrases

\begin{tabular}{|c|c|c|c|c|c|c|c|}
\hline \multirow{3}{*}{ Effect } & \multirow{3}{*}{$\begin{array}{l}\text { Acute/ } \\
\text { Chronic }\end{array}$} & \multicolumn{5}{|c|}{ Routes of Exposure } & \multirow{3}{*}{ HR } \\
\hline & & \multirow[b]{2}{*}{ Inhalation } & \multicolumn{2}{|c|}{ Dermal } & \multirow[b]{2}{*}{ Ingestion } & \multirow{2}{*}{$\begin{array}{c}\text { Not } \\
\text { specified } \\
\text { (all routes) }\end{array}$} & \\
\hline & & & Skin & EYE & & & \\
\hline \multirow{2}{*}{ Very Toxic } & Acute & $\mathrm{R} 26$ & $\mathrm{R} 27$ & & $\mathrm{R} 28$ & R39 & \multirow{2}{*}{5} \\
\hline & Chronic & - & - & & - & - & \\
\hline \multirow{2}{*}{ Toxic } & Acute & $\mathrm{R} 23$ & $\mathrm{R} 24$ & & $\mathrm{R} 25$ & R39 & \multirow{2}{*}{4} \\
\hline & Chronic & - & - & & - & R48, R39 & \\
\hline \multirow{2}{*}{ Harmful } & Acute & $\mathrm{R} 20$ & $\mathrm{R} 21$ & & R22 & $\mathrm{R} 40$ & \multirow{2}{*}{3} \\
\hline & Chronic & - & - & & - & $\mathrm{R} 48, \mathrm{R} 40$ & \\
\hline \multirow{2}{*}{ Corrosive } & \multirow{2}{*}{ Acute } & & \multicolumn{2}{|c|}{$\mathrm{R} 35$} & & & 4 \\
\hline & & & \multicolumn{2}{|c|}{ R34 } & & & 3 \\
\hline \multirow{2}{*}{ Irritant } & \multirow{2}{*}{ Acute } & R37 & - & R41 & & & 3 \\
\hline & & - & $\mathrm{R} 38$ & $\mathrm{R} 36$ & & & 2 \\
\hline \multirow{2}{*}{ Sensitizing } & \multirow{2}{*}{ Acute } & $\mathrm{R} 42$ & - & & & & 3 \\
\hline & & - & $\mathrm{R} 43$ & & & & 2 \\
\hline \multirow{3}{*}{ Carcinogenic } & \multirow{3}{*}{ Chronic } & $\mathrm{R} 49(1)$ & & & & $\mathrm{R} 45(1)$ & 5 \\
\hline & & $\mathrm{R} 49(2)$ & & & & $\mathrm{R} 45(2)$ & 4 \\
\hline & & - & & & & $\mathrm{R} 40(3)$ & 3 \\
\hline \multirow{3}{*}{ Mutagenic } & & & & & & $\mathrm{R} 46(1)$ & 5 \\
\hline & & & & & & $\mathrm{R} 46(2)$ & 4 \\
\hline & & & & & & R40(M2) & 3 \\
\hline \multirow{2}{*}{ Teratogenic } & & & & & & $\mathrm{R} 47(1)$ & 5 \\
\hline & & & & & & $\mathrm{R} 47(2)$ & 4 \\
\hline
\end{tabular}

Table 8. Matrix for Risk Rating (RR)

\begin{tabular}{clllll}
\hline \multirow{2}{*}{ Hazard Rating (HR) } & \multicolumn{5}{c}{ Exposure Rating (ER) } \\
\cline { 2 - 6 } & $\mathbf{1}$ & $\mathbf{2}$ & $\mathbf{3}$ & $\mathbf{4}$ & $\mathbf{5}$ \\
\hline $\mathbf{1}$ & 1 & 2 & 2 & 2 & 3 \\
$\mathbf{2}$ & 2 & 2 & 3 & 3 & 4 \\
$\mathbf{3}$ & 2 & 3 & 3 & 4 & 4 \\
$\mathbf{4}$ & 2 & 3 & 4 & 4 & 5 \\
$\mathbf{5}$ & 3 & 4 & 4 & 5 & 5 \\
\hline Risk not significant & & & & & \\
\hline Risk significant; category 1 & & & & & \\
\hline Risk significant; category 2 & &
\end{tabular}




\subsection{Types of Conclusions of CHRA}

Table 9 shows the conclusions of risk assessment for surveyed chemical laboratories and we used it for the identification and prioritising control measures. The degree of risk, the number of the person at risk and practicability of the control measures will determine the priority for implementing control measures.

Table 9. Risk Assessment decision and Conclusions

\begin{tabular}{lll}
\hline Risk Decision & $\begin{array}{l}\text { Adequacy of current } \\
\text { control measures }\end{array}$ & Conclusion \\
\hline $\begin{array}{l}\text { Risks not significant now and not likely to } \\
\text { increase in future }\end{array}$ & $\mathrm{C} 1$ \\
$\begin{array}{l}\text { Risk significant but already adequately } \\
\text { controlled could increase in future. }\end{array}$ & Adequate (category 1) & $\mathrm{C} 2$ \\
$\begin{array}{l}\text { Risks significant now, and not adequately } \\
\text { controlled }\end{array}$ & Not Adequate (category 2) \\
$\begin{array}{l}\text { Uncertain about } \\
\text { information }\end{array}$ & $\mathrm{C} 3$ \\
$\begin{array}{l}\text { Uncertain about Risk: Uncertain about degree } \\
\text { and extent of exposure }\end{array}$ & - & $\mathrm{C} 4$ \\
\hline
\end{tabular}

C1 - End current assessment and review every 5 years or when required.

C2 - Determine precautions, measures, the requirement for monitoring or health surveillance that been taken to maintain controls and minimize exposures. Review assessment every 5 years or when required.

C3 - Identify precautions, measures, the requirement for monitoring or health surveillance that need to be taken to maintain controls and minimize exposures. Review assessment every 5 years or when required.

C4 - Obtain more information.

C5 - Conduct more detailed assessment.

\section{Results and Discussion}

\subsection{Duration Rating (DR)}

Determination of DR used to investigate the nature of exposure i.e. chronic or routine. DR has a significant effect on chemical exposure to laboratory staff, like, 2 times the chemical exposure duration results in 2 time's chemical exposure as Table 10 shows the DR of chemical laboratories. 


\section{Macrothink}

Journal of Safety Studies

ISSN 2377-3219

2017, Vol. 3, No. 1

The total duration of chemical exposure is the product of chemical exposure and the average duration of each exposure.

Table 10. Duration rating (DR) of different occupational group

\begin{tabular}{cccc}
\hline Lab & Chemical Laboratory & Occupational Group & DR \\
\hline L1 & Analytical Chemistry Lab 1 & PhD Student & 4 \\
L2 & Natural Product Chemistry Lab & PhD Student & 4 \\
L3 & Analytical Chemistry Lab 2 & PhD Student & 4 \\
L4 & Preparation lab & PhD Student & 4 \\
L5 & Electrochemistry lab & PhD Student & 5 \\
L6 & Organic chemistry lab & Assistant Professor & 2 \\
L7 & Instrumental analysis lab & PhD Student & 4 \\
L8 & Local Ores Lab & Assistant Professor & 5 \\
L9 & Research Lab & PhD Student & 4 \\
L10 & Analytical Chemistry Lab 3 & Assistant Professor & 4 \\
L11 & Solid waste Lab & Master Student & 4 \\
L12 & Nanotechnology research lab & PhD Student & 5 \\
L13 & Plant Biotechnology Lab & PhD Student & 4 \\
L14 & Microbiology Lab & PhD Student & 5 \\
\hline
\end{tabular}

\subsection{Magnitude Rating (MR)}

The results of MR based on the degree of a chemical release (presence) and the degree of chemical absorbed (contacted) observed moderate as Table 11 shows the degree of chemical release (presence), the degree of chemical absorbed (contacted) and assigned MR.

\subsection{Exposure Rating (ER)}

Chemical laboratories categories into two types regarding the result of ER as Table 12 shows 3 and 4 values of ER.

Table 11. Degree of Chemical Release (Presence), Degree in Chemical absorbed (contacted) and assigned Magnitude rating (MR)

\begin{tabular}{ccccc}
\hline Lab & Chemical Laboratory & $\begin{array}{c}\text { Degree of Chemical } \\
\text { Release }\end{array}$ & $\begin{array}{c}\text { Degree of Chemical } \\
\text { absorbed }\end{array}$ & MR \\
\hline L1 & Analytical Chemistry Lab 1 & Moderate & Moderate & 3 \\
L2 & Natural Product Chemistry Lab & Moderate & Moderate & 3 \\
L3 & Analytical Chemistry Lab 2 & Moderate & Moderate & 3 \\
L4 & Preparation lab & Moderate & Moderate & 3
\end{tabular}


L5 Electro chemistry lab

Moderate

Moderate

L6 Organic chemistry lab

Moderate

Moderate

L7 Instrumental analysis lab

Moderate

Moderate

3

L8 Local Ores Lab

Moderate

Moderate

3

L9 Research Lab

Moderate

Moderate

3

L10 Analytical Chemistry Lab 3

Moderate

Moderate

L11 Solid waste Lab

Moderate

Moderate

L12 Nanotechnology research lab

Moderate

Moderate

3

L13 Plant Biotechnology Lab

Moderate

Moderate

3

Microbiology Lab

Moderate

Moderate

3

Table 12. Exposure rating (ER) of chemical laboratories

\begin{tabular}{ccc}
\hline Lab & Chemical Laboratory & ER \\
\hline L1 & Analytical Chemistry Lab 1 & 4 \\
L2 & Natural Product Chemistry Lab & 4 \\
L3 & Analytical Chemistry Lab 2 & 4 \\
L4 & Preparation lab & 4 \\
L5 & Electrochemistry lab & 4 \\
L6 & Organic chemistry lab & 3 \\
L7 & Instrumental analysis lab & 4 \\
L8 & Local Ores Lab & 4 \\
L9 & Research Lab & 4 \\
L10 & Analytical Chemistry Lab 3 & 4 \\
L11 & Solid waste Lab & 4 \\
L12 & Nanotechnology research lab & 4 \\
L13 & Plant Biotechnology Lab & 4 \\
L14 & Microbiology Lab & 4 \\
\hline
\end{tabular}

\subsection{Types of Conclusions of CHRA}

Two types of conclusions were made base on RR value of 4 and 5 which can be associated with the worst situation there regarding health safety of workers as Table 13 shows the results of RR and relevant conclusion for each chemical laboratories. 
Table 13. Conclusions of Risk assessment for chemical laboratories

\begin{tabular}{cccc}
\hline Lab & Chemical Laboratory & Risk rating (RR) & Conclusion \\
\hline L1 & Analytical Chemistry Lab & 5 & $\mathrm{C} 3$ \\
L2 & Natural Product Chemistry Lab & 5 & $\mathrm{C} 3$ \\
L3 & Analytical Chemistry Lab 2 & 5 & $\mathrm{C} 3$ \\
L4 & Preparation lab & 4 & $\mathrm{C} 2$ \\
L5 & Electro chemistry lab & 4 & $\mathrm{C} 2$ \\
L6 & Organic chemistry lab & 4 & $\mathrm{C} 2$ \\
L7 & Instrumental analysis lab & 4 & $\mathrm{C} 2$ \\
L8 & Local Ores Lab & 5 & $\mathrm{C} 3$ \\
L9 & Research Lab & 5 & $\mathrm{C} 3$ \\
L10 & Analytical Chemistry Lab 3 & 5 & $\mathrm{C} 3$ \\
L11 & Solid waste Lab & 5 & $\mathrm{C} 3$ \\
L12 & Nanotechnology research lab & 4 & $\mathrm{C} 2$ \\
L13 & Plant Biotechnology Lab & 4 & $\mathrm{C} 2$ \\
L14 & Microbiology Lab & 4 & $\mathrm{C} 2$ \\
\hline
\end{tabular}

The results of CHRA program shows that the risk of chemical exposure is significant in the selected chemical laboratories and there is need to improve existing control measure for the healthy working environment in the university. Involvement of top management in vital for the development of safety culture in the university. The results can be useful to mitigate the risk of chemical exposure by choosing suitable controlling measures among laboratory staff such as; Safety training, posting of safety regulations in the laboratories, departmental safety management, good housekeeping services, and use of personal protective equipment.

Table 13 shows the RR for all chemical laboratories in the selected university, half of the chemical laboratories found with $\mathrm{RR}=5$ and half of the chemical laboratories found with $\mathrm{RR}=4$ and concluded as $\mathrm{C} 3$ and $\mathrm{C} 2$ respectively. There is a strong relationship between R-phrases and $\mathrm{H}$ statements, as laboratory chemical hazards used to rate base on the R-phrases. Provided information in the SDS such as; toxicological data, health effects used to assigned R-phrases to each chemical or mixture of chemicals. So risks significantly now, and not adequately controlled in half of the chemical laboratories which need to address $\mathrm{C} 3$ which stipulates that the adequacy of current control measures be "not Adequate (category 2)" as Table 13 shows the categories of risk assessment decision and control measures. Chemical laboratories with $\mathrm{RR}=5$ considered as intolerable and need to eliminate hazardous chemicals at first. Alternatives such as; substitution of hazardous chemicals with low toxic chemicals; proper chemical management and handling; isolation of work can adopt to reduce hazardous chemical exposure among laboratory staff. For C3 immediate measures required to prevent 
from exposure such as; identification of measures and procedures to control accidental emission of hazardous chemicals; longer term control strategies; reschedule CHRA after 5 years or change in the laboratory settings. Programs of laboratory staff training and health surveillance should also be determined.

On the other hand "risk significant but already adequately controlled could increase in future" found in next half of the chemical laboratories with "Adequate (category 1)" current control measures. Chemical laboratories with $\mathrm{C} 2$ conclusion need to strengthen adequacy of control measures because the increase of RR can be possible in case of failure or deterioration of control measures. Regarding control measures, there is a need to control risks below permissible exposure limits (ALARP). The severity of risk, laboratory staff knowledge about risk, accessibility and appropriateness of eliminating or mitigating the risk and its costs can be crucial in the case of $\mathrm{C} 2$ conclusion. Factors that can be responsible for the increase of risk such as; improper use of control measures; human error due to insufficient knowledge, changes in workflow and a random rise in the chemical quantities usage. For C2, assessment can reschedule after 5 years or change in the laboratory settings. Determination of precautions and additional measures to reduce risks should be identified and evaluate their effectiveness. A previous study from Malaysia about the CHRA in chemical and biomedical engineering laboratories found $\mathrm{RR}=3$ and concluded with the $\mathrm{C} 3$ decision (Husin et al., 2012). However, this study reveals the worst situation comparatively. So the proposed mitigation in that study can be useful for lowering of RR in the chemical laboratories.

Adaptation of Globally Harmonized System of Classification and Labelling of Chemicals (GHS) is important for the reduction of chemical risk in laboratories. Globally Harmonized System of Classification and Labelling of Chemicals (GHS) has been developed for hazard communication in 1992 by United Nations Conference on the Environment and Development (UNCED). In GHS, chemicals are classified by physical, health, toxicological and environmental hazards. Harmonized labeling of chemicals and safety data sheets (SDS) use for hazards communication in the laboratories (Pratt, 2002). In a study from Taiwan, it was investigated that the perception of students towards chemical labeling and lower perception found under GHS regardless of high agreement level for chemical labeling. In the same study, students have a high perception on chemical labeling, who attended training sessions regarding hazard communication accordingly and curriculum modification was also suggested accordingly (Su \& Hsu, 2008).

Safe experiments in the chemical laboratories require safe work practices to reduce chemical exposure risk as Prudent Practices in the Laboratory, Handling and Management of Chemical Hazards book mentioned four fundamental principles for sound laboratory safety culture such as; a) Plan ahead for the determination of potential chemical hazards b) Minimum chemical exposure by using laboratory hoods, ventilation devices and personal protective equipment c) avoid underestimation of chemical hazard or related risk by treating new chemicals with unknown toxicity d) be ready for accidents during laboratory work so integrate yourself with all available laboratory safety resources such as PPEs, emergency numbers etc. (NRCC, 2011). A recent study found five factor model solution for chemical safety in academic laboratories; 1) availability of laboratory safety documents, 2) maintenance of fume hood, 3) 
proper chemical storage, 4) proper use of fume hood for chemical handling and 5) laboratory safety labelling (Abbas et al., 2016).

It is obligatory for an employer to provide hazards free workplace to his workers. Declaration of Occupational Safety and Health Administration (OSHA) Laboratory Standard (29 CFR § 1910.1450) upraised laboratory safety culture in the industrial, governmental and educational sector (NRCC, 2011), which obligate the appointment of Chemical Hygiene Officer (CHO) and Chemical Hygiene Plan (CHP). Laboratory safety guidelines developed by OSHA states that an employer must inspect workplace in case of chemical exposure above the action level. Laboratory safety provisions related to safety training, chemical exposure inspection, medical consultation, suitability of personal protective equipment (PPE), control measures, and specific guidelines for hazardous chemicals must be covered in the $\mathrm{CHP}$ and $\mathrm{CHO}$ is the prime responsible for all these provisions (OSHA, 2011).

\section{Conclusion and Recommendations}

In conclusion, chemical laboratories found with significant risk of hazardous chemical exposure. Regarding control measures, the risk of chemical exposure was not controlled adequately in half of chemical laboratories and either it was controlled in next half of the chemical laboratories but could increase in future. So, there is need to extend the current control measures to reduce risk hazardous chemical exposure among laboratory staff. Effective laboratory safety management practices are crucial for any renowned university. Results of this study and the application of CHRA program can be useful to do it in the university laboratories of other developing countries. The findings of present study proposed following suggestion which can improve occupational health and safety status of chemical laboratories in the selected university;

- Updating of hazardous chemicals registers and supplier MSDS

- Reduction of skin exposure through suitable personal protective equipment

- Assigned place for personal protective equipment

- Practical reduction of exposure to carcinogens or respiratory sensitizers

- Mandatory use of respiratory protection irrespective of absorbed dose or airborne concentration

- Proper chemical management in chemical laboratories

- Immediate notification related to new unsafe practice from chemical laboratories

- Development of emergency response plan and its follow-up training

- Implementation of employee exposure monitoring program

- Development of health surveillance programs for laboratory staff

- Development of laboratory safety training programs and evaluation

- Reassessment of CHRA after the implementation of suggested control measures 


\section{Acknowledgement}

We acknowledge the valuable commitment and cooperation of top management of University's Deanship of Graduate Studies and laboratory staff for this study.

\section{References}

Abbas, M., Zakaria, A. M., Balkhyour, M. A., \& Kashif, M. (2016). Chemical Safety in Academic Laboratories: An Exploratory Factor Analysis of Safe Work Practices \& Facilities in a University. Journal of Safety Studies, 2(1), 1-14. http://dx.doi.org/10.5296/jss.v2i1.8962.

Abbas, M., Zakaria, A. M., \& Balkhyour, M. A. (2016). Investigation of safety facilities and safe practices in chemical laboratories of a Saudi university. Journal of Environment and Safety, 7(2), 141-147.

Apostoli, P., Lucchini, R., \& Alessio, L. (1996). Proposal of a method for identifying exposure to hazardous chemicals in biomedical laboratories. Clinica chimica acta, 256(1), 75-86. http://dx.doi.org/10.1016/S0009-8981(96)06416-9.

Chemical Health Risk Assessment (CHRA), 2000. [Internet] accessed on February 11, 2017. Available from http:/www.dosh.gov.my/index.php/en/legislation/guidelines/chemical/627-0 8-assessment-of-the-health-risks-arising-from-the-use-of-hazardous-chemical-in-the-workpla ce-2nd-edition-2000/file

Bourrée, F., Salmi, L. R., Garrigou, A., Domecq, S., Brochard, P., \& Michel, P. (2014). A comparison of three methods to identify chemicals hazards in French research laboratories. Safety Science, 68, 324-330. http://dx.doi.org/10.1016/j.ssci.2014.03.010

Freemantle, M. (2006). Blast kills French chemistry professor. Chemical and engineering news, 84(14), 13.

Husin, S. N. H., Mohamad, A. B., Abdullah, S. R. S., \& Anuar, N. (2012). Chemical Health Risk Assessment at The Chemical and Biochemical Engineering Laboratory. Procedia-Social and Behavioral Sciences, 60, 300-307. http://dx.doi.org/10.1016/j.sbspro.2012.09.383.

Keil, C., \& Murphy, R. (2006). An application of exposure modeling in exposure assessments for a university chemistry teaching laboratory. Journal of occupational and environmental hygiene, 3(2), 99-106. DOI:10.1080/15459620500498109.

Kemsley, J., \& Baum, R. (2010). Texas tech lessons. Chemical \& Engineering News, 88(34), 34-37.

Leggett DJ. Lab-HIRA: Hazard identification and risk analysis for the chemical research laboratory: Part 1. Preliminary hazard evaluation. 2012a. Journal of Chemical Health and Safety. 31;19(5), 9-24. DOI: 10.1016/j.jchas.2012.01.012.

Leggett DJ. Lab-HIRA: Hazard identification and risk analysis for the chemical research laboratory. Part 2. Risk analysis of laboratory operations. 2012b. Journal of Chemical Health and Safety. 31;19(5):25-36. http://dx.doi.org/10.1016/j.jchas.2012.01.013. 


\section{Macrothink}

Journal of Safety Studies

ISSN 2377-3219

2017, Vol. 3, No. 1

Leggett DJ. Identifying hazards in the chemical research laboratory. 2012c. Process Safety Progress. 1;31(4):393-7. DOI: 10.1002/prs.11518.

Marendaz, J. L., Suard, J. C., \& Meyer, T. (2013). A systematic tool for Assessment and Classification of Hazards in Laboratories (ACHiL). Safety science, 53, 168-176.

Meyer, T. (2012). How about safety and risk management in research and education?. Procedia Engineering, 42, 854-864.

National Research Council (US) Committee (NRCC): Prudent Practices in the Laboratory, Handling and Management of Chemical Hazards, US, National Academies Press, 2011.

Occupational Safety and Health Act (OSHA), 2011. Laboratory Safety Guidance 3404-11R 2011.

https://www.osha.gov/Publications/laboratory/OSHA3404laboratory-safety-guidance.pdf.

Ouédraogo, A., Groso, A., \& Meyer, T. (2011). Risk analysis in research environment-Part I: Modeling lab criticity index using improved risk priority number. Safety science, 49(6), 778-784. http://dx.doi.org/10.1016/j.ssci.2011.02.006.

Pratt, I. S. (2002). Global harmonisation of classification and labelling of hazardous chemicals. Toxicology letters, 128(1), 5-15.

Shariff, A. M., \& Norazahar, N. (2012). At-risk behaviour analysis and improvement study in an academic laboratory. Safety science, 50(1), 29-38. DOI: 10.1016/j.ssci.2011.06.008.

Su, T. S., \& Hsu, I. Y. (2008). Perception towards chemical labeling for college students in Taiwan using Globally Harmonized System. Safety science, 46(9), 1385-1392.

Tobiszewski, M., \& Namieśnik, J. (2015). Scoring of solvents used in analytical laboratories by their toxicological and exposure hazards. Ecotoxicology and environmental safety, 120, 169-173. http://dx.doi.org/10.1016/j.ecoenv.2015.05.043.

Wu, T. C., Liu, C. W., \& Lu, M. C. (2007). Safety climate in university and college laboratories: Impact of organizational and individual factors. Journal of Safety Research, 38(1), 91-102. http://dx.doi.org/10.1016/j.jsr.2007.01.003.

\section{Glossary}

CHRA: Chemical Health Risk Assessment

DR: Duration Rating

MR: Magnitude Rating

ER: Exposure Rating

HR: Hazard Rating

RR: Risk Rating 


\section{Macrothink}

Journal of Safety Studies

ISSN 2377-3219

2017, Vol. 3, No. 1

\section{Copyrights}

Copyright for this article is retained by the author(s), with first publication rights granted to the journal.

This is an open-access article distributed under the terms and conditions of the Creative Commons Attribution license (http://creativecommons.org/licenses/by/4.0/) 